\title{
Sarcoplasmic Reticulum Calcium ATPase Is Inhibited by Organic Vanadium Coordination Compounds: Pyridine-2,6-dicarboxylatodioxovanadium(V), BMOV, and an Amavadine Analogue
}

\author{
Manuel Aureliano, ${ }^{,, t, \neq}$ Fernando Henao, ${ }^{\S}$ Teresa Tiago, ${ }^{\dagger, \ddagger}$ Rui O. Duarte," J. J. G. Moura," \\ Bharat Baruah, ${ }^{\perp}$ and Debbie C. Crans ${ }^{*, \perp}$ \\ Dept. Química, Bioquímica e Farmácia, FCT, Universidade do Algarve, 8005-139 Faro, Portugal, \\ CCMar, Universidade do Algarve, Faro, Portugal, Dept. Bioquímica y Biología Molecular, \\ Facultad de Ciencias, Universidad de Extremadura, Badajoz, Spain, REQUIMTE, Dept. Química, \\ FCT, Universidade Nova de Lisboa, Monte da Caparica, Portugal, and Department of Chemistry, \\ Colorado State University, Fort Collins, Colorado 80523-1872
}

Received December 12, 2007

\begin{abstract}
The general affinity of the sarcoplasmic reticulum (SR) $\mathrm{Ca}^{2+}$-ATPase was examined for three different classes of vanadium coordination complexes including a vanadium(V) compound, pyridine-2,6-dicarboxylatodioxovanadium(V) $(\mathrm{PDC}-\mathrm{V}(\mathrm{V}))$, and two vanadium(IV) compounds, bis(maltolato)oxovanadium(IV) (BMOV), and an analogue of amavadine, bis(N-hydroxylamidoiminodiacetato)vanadium(IV) (HAIDA-V(IV)). The ability of vanadate to act either as a phosphate analogue or as a transition-state analogue with enzymes' catalysis phosphoryl group transfer suggests that vanadium coordination compounds may reveal mechanistic preferences in these classes of enzymes. Two of these compounds investigated, $\mathrm{PDC}-\mathrm{V}(\mathrm{V})$ and $\mathrm{BMOV}$, were hydrolytically and oxidatively reactive at neutral $\mathrm{pH}$, and one, HAIDA-V(IV), does not hydrolyze, oxidize, or otherwise decompose to a measurable extent during the enzyme assay. The SR $\mathrm{Ca}^{2+}$-ATPase was inhibited by all three of these complexes. The relative order of inhibition was PDC $-\mathrm{V}(\mathrm{V})>\mathrm{BMOV}>$ vanadate $>\mathrm{HAIDA}-\mathrm{V}(\mathrm{IV})$, and the $\mathrm{IC}_{50}$ values were $25,40,80$, and $325 \mu \mathrm{M}$, respectively. Because the observed inhibition is more potent for $\mathrm{PDC}-\mathrm{V}(\mathrm{V})$ and $\mathrm{BMOV}$ than that of oxovanadates, the inhibition cannot be explained by oxovanadate formation during enzyme assays. Furthermore, the hydrolytically and redox stable amavadine analogue HAIDA-V(IV) inhibited the $\mathrm{Ca}^{2+}$-ATPase less than oxovanadates. To gauge the importance of the lipid environment, studies of oxidized BMOV in microemulsions were performed and showed that this system remained in the aqueous pool even though $P D C-V(V)$ is able to penetrate lipid interfaces. These findings suggest that the hydrolytic properties of these complexes may be important in the inhibition of the calcium pump. Our results show that two simple coordination complexes with known insulin enhancing effects can invoke a response in calcium homeostasis and the regulation of muscle contraction through the SR $\mathrm{Ca}^{2+}$-ATPase.
\end{abstract}

\section{Introduction}

Vanadium oxoanions are known to inhibit or stimulate many enzymes ${ }^{1-7}$ such as the membrane-bound E1-E2

* Corresponding author: E-mail: maalves@ualg.pt (M.A.); crans@ lamar.colostate.edu (D.C.C.).

Dept. Química, Bioquímica e Farmácia, FCT, Universidade do Algarve.

*CMar, Universidade do Algarve.

$\S$ Dept. Bioquímica y Biología Molecular, Facultad de Ciencias, Universidad de Extremadura.

"Dept. Química, FCT, Universidade Nova de Lisboa.

${ }^{\perp}$ Department of Chemistry, Colorado State University.

(1) Kustin, K.; Pessoa, J. C.; Crans, D. C. Vanadium the Versatile Metal (ACS Symposium Series); Oxford University Press: New York, 2007; Vol. 974.
$\mathrm{Ca}^{2+}$-ATPase. ${ }^{8,9}$ Because vanadate can act as a transitionstate analogue as well as a phosphate analogue, the details

(2) Chasteen, N. D. In Metal Ions in Biological Systems; Sigel, H., Sigel, A., Eds.; Marcel Dekker, Inc.: New York, 1995; Vol. 31, pp 231-248.

(3) Chasteen, N. D. In Struct. Bonding (Berlin); Clarke, M. J., Goodenough, J. B., Ibers, J. A., Jørgensen, C. K., Mingos, D. M. P., Neilands, J. B., Palmer, G. A., Reinen, D., Sadler, P. J., Weiss, R., Williams, R. J. P., Eds.; Springer-Verlag: New York, 1983; Vol. 53, p $105-138$.

(4) Butler, A.; Walker, J. V. Chem. Rev. 1993, 93, 1937-1944.

(5) Crans, D. C. Comm. Inorg. Chem. 1994, 16, 35-76.

(6) Crans, D. C.; Smee, J. J.; Gaidamauskas, E.; Yang, L. Chem. Rev. 2004, 104, 849-902.

(7) Crans, D. C. Pure Appl. Chem. 2005, 77, 1497-1527.

(8) Krebs, J.; Vasak, M.; Scarpa, A.; Carafoli, E. Biochemistry 1987, 26, 3921-3926. 
of the mode of inhibition are often not clear and inhibition of organic vanadium complexes can be of mechanistic importance to sort out the different modes of action. ${ }^{1,2,6}$ The active site of the $\mathrm{Ca}^{2+}$-ATPase, a calcium pump, contains an aspartyl residue that is phosphorylated during the catalytic cycle, thereby forming an acyl phosphate anhydride. ${ }^{10}$ The mechanism of the inhibition by vanadate is attributed to the blocking by vanadate of the formation of the E2 conformation of the $\mathrm{Ca}^{2+}$-ATPase from the sarcoplasmic reticulum (SR). ${ }^{8}$ How vanadate oligomers interact with the SR calcium pump and inhibit its activity have been investigated. ${ }^{9,11}$ For instance, decameric vanadate species $\left(\mathrm{V}_{10}\right)$ in functional SR vesicles (absence of calcium ionophore) inhibit calcium accumulation coupled with ATP hydrolysis, whereas monomeric vanadate $\left(\mathrm{V}_{1}\right)$ has no effects. ${ }^{11}$ Moreover, other vanadate species, for example tetrameric vanadate species $\left(\mathrm{V}_{4}\right)$, may also have an implicit effect on $\mathrm{H}^{+}$ejection associated with calcium translocation. ${ }^{9}$ In fact, the SR calcium pump has proven to be an excellent model to study the effects of vanadium in $\mathrm{Ca}^{2+}$ homeostasis, particularly in instances where some oxovanadates have been found to disrupt energy coupling and enzyme turnover. ${ }^{9}$ Recently, decreased SR calcium pump activity was reported under specific conditions associated with diabetes that could result in impaired cardiac relaxation. ${ }^{12}$

Many vanadium compounds are known to have insulinlike or insulin-enhancing effects on several animal model systems. ${ }^{6,13-16}$ Studies have been carried out with simple salts and coordination complexes of vanadium in oxidation states III, IV, ${ }^{6,13,14,16}$ and V. ${ }^{6,15,16}$ In addition to the animal studies, a range of studies was also carried out in several cellular systems, which probed the activity of specific classes of vanadium compounds and how these compounds act. ${ }^{17-19}$ In such biological studies, the nature of the active vanadium compound cannot readily be identified, and consideration of chemical and metabolic processing is difficult. ${ }^{6,15,16}$ However, various approaches to address this problem have provided some further insight as to the biological activity

(9) Aureliano, M.; Madeira, V. M. C. In Vanadium in the Environment, Part 1: Chemistry and Biochemistry; Nriagu, J. O., Ed.; John Wiley \& Sons, Inc.: New York, 1998, pp 333-357.

(10) de Meis, L.; Vianna, A. L. Annu. Rev. Biochem. 1979, 48, 275-92.

(11) Aureliano, M.; Madeira, V. M. Biochim. Biophys. Acta 1994, 1221, 259-271.

(12) Bidasee, K. R.; Zhang, Y.; Shao, C. H.; Wang, M.; Patel, K. P.; Dincer, U. D.; Besch, H. R., Jr. Diabetes 2004, 53, 463-473.

(13) Sakurai, H. Chem. Rec. 2002, 2, 237-248.

(14) Melchior, M.; Rettig, S. J.; Liboiron, B. D.; Thompson, K. H.; Yuen, V. G.; McNeill, J. H.; Orvig, C. Inorg. Chem. 2001, 40, 4686-4690.

(15) Thompson, K.; Orvig, C. J. Chem. Soc., Dalton Trans. 2000, 28852892.

(16) Buglyo, P.; Crans, D. C.; Nagy, E. M.; Lindo, R. L.; Yang, L.; Smee, J. J.; Jin, W.; Chi, L.-H.; Godzala, M. E.; Willsky, G. R. Inorg. Chem. 2005, 44, 5416-5427.

(17) Rehder, D.; Pessoa, J. C.; Geraldes, C. F. G. C.; Castro, M. M. C. A.; Kabanos, T.; Kiss, T.; Meier, B.; Micera, G.; Pettersson, L.; Rangel, M.; Salifoglou, A.; Turewl, I.; Wang, D. J. Biol. Inorg. Chem. 2002, 7, 384-396.

(18) Etcheverry, S. B.; Cortizo, A. M. In Vanadium in the Environment. Part 1: Chemistry and Biochemistry; Nriagu, J. O., Ed.; John Wiley \& Sons, Inc.: New York, 1998, pp 359-394.

(19) Cortizo, A. M.; Bruzzone, L.; Molinuevo, S.; Etcheverry, S. B. Toxicology 2000, 147, 89-99. of these compounds. ${ }^{5-7,16,20}$ Information on how effectively specific compounds inhibit isolated enzymes is important for consideration of their mode of actions in cells and animals. ${ }^{6}$

A range of studies of a few vanadium compounds on isolated enzyme systems have been reported where the species exerting the effects can be more rigorously tracked. ${ }^{5,21,22}$ Most of these studies were carried out with phosphatases and kinases, ${ }^{21,22}$ but some studies with proteins in other metabolic pathways ${ }^{5,23,24}$ including the $\mathrm{Ca}^{2+}$-ATPase are available. ${ }^{25}$ Vanadium complexes are generally found to be inhibitors, although the potency of the compounds varies widely from millimolar to nanomolar efficacy. ${ }^{6}$ The effects of oxovanadates have been reported on a range of isolated classes of enzymes such as phosphorylases and dehydrogenases, and include application of vanadate as a structural probe in X-ray diffraction studies of proteinvanadate complexes. ${ }^{26}$ In this work, we consider the effects of three very different classes of vanadium compounds, two of which are known to induce insulin-enhancing effects ${ }^{16,27}$ and a third class that is a well-known analogue of a vanadium-containing natural product. ${ }^{28-31}$ The vanadiumcontaining natural product is very different from the other two vanadium compounds with regard to structure and properties (Figure 1).

Conversion of vanadium complexes to simple vanadate oligomers $^{5,16}$ and salts in the biological system complicate the interpretation of the effects of the compounds and is not generally considered. Even in the micromolar range, oxovanadates can induce specific responses in enzymes such as phosphohydrolases ${ }^{5,32,33}$ and, therefore, effects observed in vivo $^{20,34-38}$ may be, in part, due to the action of species such as decavanadate $\left(\mathrm{V}_{10}\right),{ }^{38}$ vanadate monomer, ${ }^{5}$ or vanadyl

(20) Thompson, K. H.; Liboiron, B. D.; Hanson, G. R.; Orvig, C. In Medicinal Inorganic Chemistry; Sessler, J. L., Doctrow, S. R., McMurry, T. J., Lippard, S. J., Eds.: ACS Symposium Series, Vol. 903, Chap. 21: 385-399, American Chemical Society: Washington, DC, 2005.

(21) Posner, B. I.; Faure, R.; Burgess, J. W.; Bevan, A. P.; Lachance, D.; Zhang-Sun, G.; Fantus, I. G.; Ng, J. B.; Hall, D. A.; Lum, B. S.; Shaver, A. J. Biol. Chem. 1994, 269, 4596-4604.

(22) Crans, D. C.; Keramidas, A. D.; Drouza, C. Phosphorus, Sulfur, Silicon Relat. Elem 1996, 109-110, 245-248.

(23) Mustafi, D.; Bekesi, A.; Vertessy, B. G.; Makinen, M. W. Proc. Natl. Acad. Sci. U.S.A. 2003, 100, 5670-5675.

(24) Ou, H. S.; Yan, L. M.; Mustafi, D.; Makinen, M. W.; Brady, M. J. J. Biol. Inorg. Chem. 2005, 10, 874-886.

(25) Aureliano, M.; Tiago, T.; Gândara, R. M.; Sousa, A.; Moderno, A.; Kaliva, M.; Salifoglou, A.; Duarte, R. O.; Moura, J. J. J. Inorg. Biochem. 2005, 99, 2355-2361.

(26) Davies, D. R.; Hol, W. G. J. FEBS Lett. 2004, 577, 315-321.

(27) McNeill, J. H.; Yuen, V. G.; Hoveyda, H. R.; Orvig, C. J. Med. Chem. 1992, 35, 1489-1491.

(28) Garner, C. D.; Armstrong, E. M.; Berry, R. E.; Beddoes, R. L.; Collison, D.; Cooney, J. J.; Ertok, S. N.; Helliwell, M. J. Inorg. Biochem. 2000, 80, 17-20.

(29) Anderegg, G.; Koch, E.; Bayer, E. Inorg. Chim. Acta 1987, 127, 183 188.

(30) Bayer, E.; Koch, E.; Anderegg, G. Angew. Chem., Int. Ed. Engl. 1987, 26, 545-546.

(31) Kneifel, H.; Bayer, E. J. Am. Chem. Soc. 1986, 108, 3075-3077.

(32) Tiago, T.; Aureliano, M.; Gutierrez-Merino, C. Biochemistry 2004, 43, 5551-5561.

(33) Tiago, T.; Aureliano, M.; Moura, J. J. J. Inorg. Biochem. 2004, 98, 1902-1910.

(34) Aureliano, M.; Joaquim, N.; Sousa, A.; Martins, H.; Coucelo, J. M. J. Inorg. Biochem. 2002, 90, 159-165.

(35) Willsky, G. R.; White, D. A.; McCabe, B. C. J. Biol. Chem. 1984, 259, 13273-13281. 


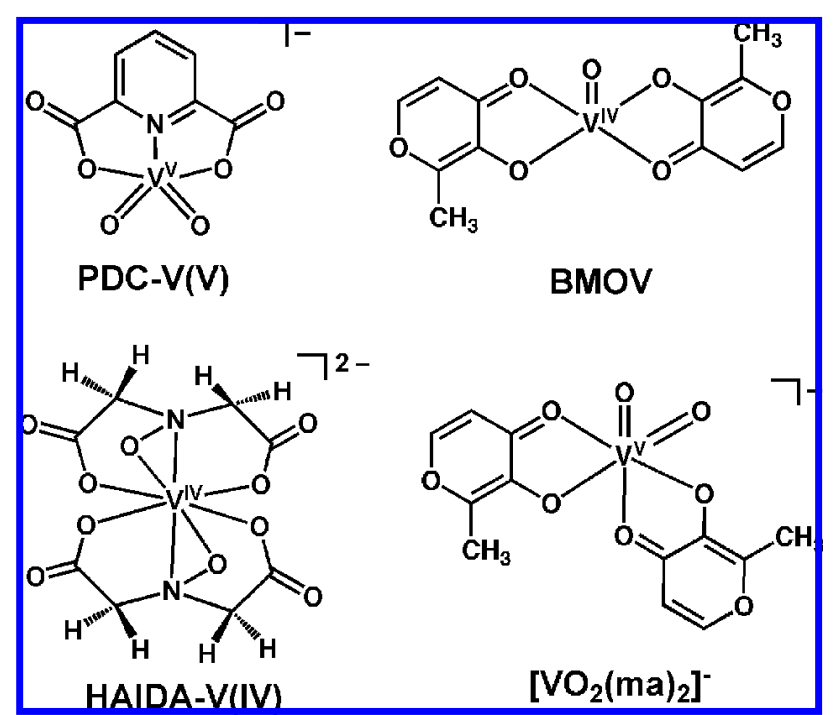

Figure 1. Molecular structures of PDC-V(V), BMOV, HAIDA-V(IV), and $\left[\mathrm{VO}_{2}(\mathrm{ma})_{2}\right]^{-}$.

cation. ${ }^{5,23,24,39}$ Combining biochemical kinetic studies with analysis by ${ }^{51} \mathrm{~V}$ NMR spectroscopy, ${ }^{9,11}$ it is possible to correlate inhibition with the presence of specific vanadate species as has previously been reported. . $^{5,9,11,23,24,26}$

In the present study, the effects of three vanadium complexes, namely pyridine-2,6-dicarboxylatodioxovanadi$\mathrm{um}(\mathrm{V}) \quad(\mathrm{PDC}-\mathrm{V}(\mathrm{V})),{ }^{16}$ bis(maltolato)oxovanadium(IV) $(\mathrm{BMOV})^{27}$ and an analogue of amavadine, bis( $N$-hydroxylamidoiminodiacetato)vanadium(IV) HAIDA-V(IV), ${ }^{28}$ on $\mathrm{SR} \mathrm{Ca}^{2+}$-ATPase activity were evaluated (Figure 1). The two complexes known to interconvert to other species at neutral $\mathrm{pH}$ and in the presence of oxygen were studied to examine the extent of conversion of these systems to other vanadi$\mathrm{um}(\mathrm{V})$ species and to determine whether the resulting species interact with the SR calcium pump. The most-potent inhibition observed for the PDC $-\mathrm{V}(\mathrm{V})$ complex exceeded that of vanadate solutions reported previously ${ }^{11}$ and provided compelling evidence that the observed inhibition cannot simply be due to conversion of the complex to oxovanadate. ${ }^{6}$

\section{Materials and Methods}

Reagents. Reagent-grade chemicals were used to prepare buffers. Ammonium metavanadate was purchased from Riedel-de Haën. ATP (vanadium free) was supplied by Sigma. All other reagents were of biochemical analysis grade from BDH, Merck, or Sigma.

The synthesis of the vanadium complexes was performed as described previously for pyridine-2,6-dicarboxylatodioxovanadium(V) PDC-V(V)), ${ }^{16}$ bis(maltolato)oxovanadium(V) $(\mathrm{BMOV})^{40}$ and the simple amavadine analogue bis( $N$-hydroxylamidoimino-

(36) Willsky, G. R.; Leung, J. O.; Offermann, P. V., Jr.; Plotnick, E. K.; Dosch, S. F. J. Bacteriol. 1985, 164, 611-617.

(37) Gândara, R. M.; Soares, S. S.; Martins, H.; Gutierrez-Merino, C.; Aureliano, M. J. Inorg. Biochem. 2005, 99, 1238-1244.

(38) Aureliano, M.; Gândara, R. M. J. Inorg. Biochem. 2005, 99, 979985.

(39) Chasteen, N. D.; DeKoch, R. J.; Rogers, B. L.; Hanna, M. W. J. Am. Chem. Soc. 1973, 95, 1301-1309.

(40) Caravan, P.; Gelmini, L.; Glover, N.; Herring, F. G.; Li, H. L.; McNeill, J. H.; Rettig, S. J.; Setyawati, I. A.; Shuter, E.; Sun, Y.; Tracey, A. S.; Yuen, V. G.; Orvig, C. J. Am. Chem. Soc. 1995, 117, 12759-12770.
diacetato)vanadium(IV), HAIDA-V(IV). ${ }^{28,41}$ The chemistry of these systems is well-described and predicts that a minor fraction of the PDC $-\mathrm{V}(\mathrm{V})$ complex would retain its structural identity during the enzyme assay; ${ }^{16}$ however, a larger fraction of $\mathrm{BMOV}^{6,7,14}$ and all of the amavadine analogue remain in their original form. ${ }^{6,7,29,30}$ These predictions are based on reports that the PDC- $\mathrm{V}(\mathrm{V})$ complexes are hydrolyzed and reduced at neutral $\mathrm{pH}$ and under physiological conditions ${ }^{6,7} \mathrm{BMOV}$ is known to oxidize in solution $^{6,7,14}$ but amavadine is stable..$^{6,7,29,30}$

Stock solutions $(9 \mathrm{mM})$ of vanadium complexes were prepared from pyridine-2,6-dicarboxylatodioxovanadium(V) (PDC-V(V)), bis(maltolato)oxovanadium(IV) (BMOV), and amavadine-analogue HAIDA-V(IV) in water or in media containing $25 \mathrm{mM}$ HEPES (2-(4-(2-hydroxyethyl)-1-piperazinyl)ethanesulfonic acid), $\mathrm{pH}$ 7.0, and $0.1 \mathrm{M} \mathrm{KCl}$, immediately prior to use in studies.

Preparation of Sarcoplasmic Reticulum Vesicles. Sarcoplasmic reticulum vesicles (SRV) were prepared from skeletal rabbit muscles as described elsewhere. ${ }^{11,42}$ For activity measurements, the SR were isolated from rabbits that had been subjected to a $48 \mathrm{~h}$ starvation $\operatorname{diet}^{43}$ to decrease the amount of glycogen phosphorylase associated with the SR membranes. Isolated SR vesicles suspended in $0.1 \mathrm{M} \mathrm{KCl}, 10 \mathrm{mM}$ HEPES ( $\mathrm{pH}$ 7.0) were diluted 1:1 with $2.0 \mathrm{M}$ sucrose and frozen in liquid nitrogen prior to storage at $-80{ }^{\circ} \mathrm{C}$. For SR-vesicle preparations used in NMR studies, sucrose was omitted from sample preparations because sucrose is known to form complexes with vanadate. ${ }^{9,11}$ Protein concentration was determined spectrophotometrically at $280 \mathrm{~nm}$ by the Biuret method, using bovine serum albumin as a standard ${ }^{44}$ and in the presence of $1 \%$ of sodium dodecyl sulfate. ${ }^{45}$ The percentage of each protein present in the SR-vesicle preparations was determined through densitometry analysis of sodium dodecyl sulfate (SDS)-polyacrylamide gel electrophoresis (7.5\% acrylamide). The SR $\mathrm{Ca}^{2+}$-ATPase analyzed by SDSpolyacrylamide gel electrophoresis was at least $70 \%$ of the total protein in the SR-vesicles. The SERCA 1, sarcoplasmic, or endoplasmic reticulum $\mathrm{Ca}^{2+}$-ATPase 1 was found as the predominant isoform in our SR preparations. ${ }^{45}$

NMR Measurements. Vanadium-51 $\left({ }^{51} \mathrm{~V}\right)$ nuclear magnetic resonance spectroscopy measurements on vanadium complex solutions were recorded on a Bruker AM- $400 \mathrm{MHz}$ or a Varian Inova $400 \mathrm{MHz}$ spectrometer using a $90^{\circ}$ pulse angle. Chemical shift values are referenced to a $\mathrm{VOCl}_{3}(0.00 \mathrm{ppm})$ standard. The relative areas of vanadium $(\mathrm{V})$ resonances were integrated, and the line widths were obtained by subtracting the $20 \mathrm{~Hz}$ line broadening used in the data processing. The concentrations of vanadium(V) species were calculated from the fractions of the total integrated areas observed in the recorded spectra as described elsewhere. ${ }^{5,11}$

The ${ }^{51} \mathrm{~V}$ NMR spectra of solutions of vanadium complexes $(\mathrm{PDC}-\mathrm{V}(\mathrm{V})$ and oxidized $\mathrm{BMOV})$ were obtained at several concentrations in the reaction medium, containing $0.1 \mathrm{M} \mathrm{KCl}, 5.0$ $\mathrm{mM} \mathrm{MgCl} 2,50 \mu \mathrm{M} \mathrm{CaCl}_{2}$, and $500 \mu \mathrm{M}$ ATP in $25 \mathrm{mM}$ (pH 7.0) HEPES. Spectra of the complexes were obtained in the reaction medium at ambient temperature, in the absence or presence of SR preparations (up to $10 \mathrm{mg} / \mathrm{mL}$ ). The spectral parameters for these

(41) Smith, P. D.; Berry, R. E.; Harben, S. M.; Beddoes, R. L.; Helliwell, M.; Collison, D.; Garner, C. D. J. Chem. Soc., Dalton Trans. 1997, 4509-4516.

(42) Henao, F.; Gutierrez-Merino, C. Biochim. Biophys. Acta 1989, 984 , $135-142$.

(43) Cuenda, A.; Henao, F.; Nogues, M.; Gutierrez-Merino, C. Biochim. Biophvs. Acta 1994, 1194, 35-43.

(44) Gornall, A. G.; Bardawill, C. J.; David, M. M. J. Biol. Chem. 1949, 177, 751-766.

(45) De Foresta, B.; Henao, F.; Champeil, P. Eur. J. Biochem. 1994, 223 , 359-369. 
solutions were spectral width $40355 \mathrm{~Hz}$, accumulation time $0.05 \mathrm{~s}$, number of transients between 12000 and 25000 , and a relaxation delay of $0.01 \mathrm{~s}$. These parameters were held constant for all quantitative measurements. ${ }^{11}$

EPR Measurements. EPR spectra were obtained with a conventional X-band Bruker EMX 6/1 spectrometer equipped with a Bruker ER4116DM dual mode cavity. An Oxford ESR900 continuous-flow cryostat was used. The spectra of frozen solutions were acquired at $77 \mathrm{~K}$ using $0.2 \mathrm{~mL}$ of samples. Typical measurement conditions for CW-EPR were field modulation frequency, $100 \mathrm{kHz}$; modulation amplitude, $10 \mathrm{G}$; receiver gain, $5.02 \times 10^{4}$; time constant, $40.96 \mathrm{~ms}$; sweep time $167.77 \mathrm{~s}$; microwave power, 0.2 $\mathrm{mW}$; and the number of scans, 4.

ATP Hydrolysis By Calcium Pump. Steady-state assays of the sarcoplasmic reticulum $\mathrm{Ca}^{2+}$-ATPase were measured spectrophotometrically at $25{ }^{\circ} \mathrm{C}$, using the coupled enzyme pyruvate kinase/ lactate dehydrogenase assay ${ }^{45}$ under the following conditions: 25 mM HEPES (pH 7.0), $100 \mathrm{mM} \mathrm{KCl,} 5 \mathrm{mM} \mathrm{MgCl}, 50 \mu \mathrm{M} \mathrm{CaCl}_{2}$, $2.5 \mathrm{mM}$ ATP, $0.42 \mathrm{mM}$ phosphoenolpyruvate, $0.25 \mathrm{mM} \mathrm{NADH}$, 18 IU lactate dehydrogenase, and 7.5 IU pyruvate kinase. The experiments were initiated after the addition of $10 \mu \mathrm{g} / \mathrm{ml}$ protein in the presence of $4 \%(\mathrm{w} / \mathrm{w})$ of calcium ionophore A23187 and followed for $10 \mathrm{~min}$. Vanadium complex solutions were added to the medium prior to protein addition. The absorbance of the vanadium complexes had no effect on the observation of the rapid decrease in absorbance at $340 \mathrm{~nm}$ upon addition of $40 \mu \mathrm{M}$ ADP after the assay.

Model Microemulsion Preparation. The microemulsion model system (reverse micelles, RMs, AOT/isooctane $/ \mathrm{H}_{2} \mathrm{O}$ ) were prepared by pipetting the solution of $\left[\mathrm{VO}_{2}(\mathrm{ma})_{2}\right]^{-}$(the oxidized form of BMOV, Figure 1$)^{40}$ at $\mathrm{pH} 4.4,5.9$, and 7.6, into aliquots of the $0.500 \mathrm{M}$ AOT (sodium bis(2-ethylhexyl) sulfosuccinate) stock solution in isooctane. $\left[\mathrm{VO}_{2}(\mathrm{ma})_{2}\right]^{-}$was prepared from $60 \mathrm{mM}$ $\mathrm{NaVO}_{3}$ and $120 \mathrm{mM}$ maltol (3-hydroxy-2-methyl-4-pyrone) to form the $1: 2$ complex in $\mathrm{D}_{2} \mathrm{O}$ as described previously. ${ }^{40}$ All samples were mixed by shaking prior to spectroscopic measurements, and the resulting solutions were transparent. Dynamic light scattering experiments were performed to demonstrate that RMs form in solution and to measure their size and polydispersity (DynaProMSTC) as reported previously. ${ }^{46}$

\section{Results and Discussion}

We find that the addition of the three different vanadium complexes, PDC-V(V), BMOV, and HAIDA-V(IV), has markedly different effects from oxovanadate on the activity of the calcium ATPase from the sarcoplasmic reticulum. The ATPase activity is measured by coupling pyruvate dehydrogenase/lactate dehydrogenase oxidation of NADH and plotted as a percentage activity compared to the observed activity in the absence of test compound. All three vanadium compounds inhibit the ATP hydrolysis, with the PDC $-\mathrm{V}(\mathrm{V})$ inhibiting the hydrolysis at lower concentrations. The $50 \%$ inhibition level was observed for PDC-V(V) and BMOV at $25 \mu \mathrm{M}$ and $40 \mu \mathrm{M}$, respectively (part A of Figure 2). The amavadine analogue HAIDA-V(IV) also inhibits the enzymatic activity but to a lower extent, with an $\mathrm{IC}_{50}$ value of $325 \mu \mathrm{M}$ (part B of Figure 2). The inhibition is observed at compound levels higher than typically administered in animal studies; ${ }^{6,15,20,40}$ however, it is not uncommon that the

(46) Maitra, A. J.Phys. Chem. 1984, 88, 5122-5125.

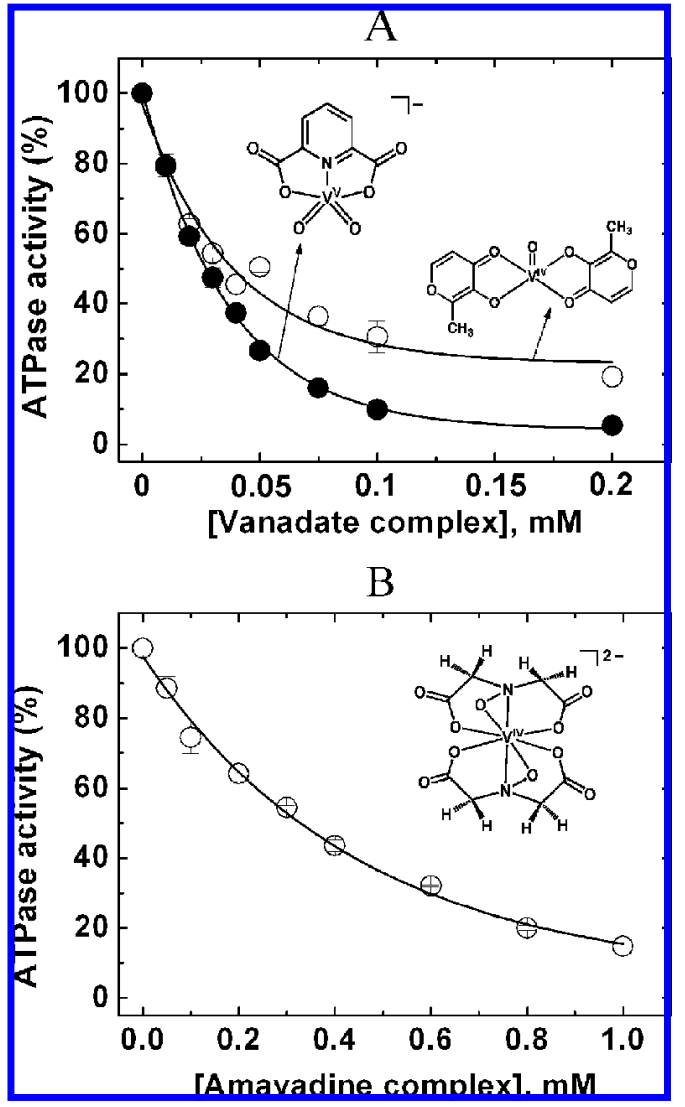

Figure 2. Effects of (A) BMOV (O) and PDC-V(V) (-), (B) HAIDAV(IV) on $\mathrm{Ca}^{2+}$-ATPase activity by the SR calcium pump. Sarcoplasmic reticulum vesicles, $10 \mu \mathrm{g} / \mathrm{ml}$, were incubated during $5 \mathrm{~min}$ at $25^{\circ} \mathrm{C}$ in a medium containing $25 \mathrm{mM}$ HEPES (pH 7.0), $100 \mathrm{mM} \mathrm{KCl}, 5.0 \mathrm{mM} \mathrm{MgCl}$, $50 \mu \mathrm{M} \mathrm{CaCl}_{2}, 0.42 \mathrm{mM}$ phosphoenolpyruvate, $0.25 \mathrm{mM} \mathrm{NADH}$, and the concentration of the vanadium complexes in $(\mathrm{A})(\mathrm{PDC}-\mathrm{V}(\mathrm{V})(-)$ and BMOV (O)) and (B) (HAIDA-V(IV)) was varied as indicated on the abscissa. After the incubation, 18 IU lactate dehydrogenase plus $7.5 \mathrm{IU}$ pyruvate kinase, $0.4 \mu \mathrm{g} / \mathrm{ml} \mathrm{A23187,} \mathrm{and} 2.5 \mathrm{mM}$ ATP were added to the medium. The ATPase activity was measured as indicated in the Materials and Methods section. Experimental values are means of at least 3 different experiments with 3 different sarcoplasmic reticulum vesicles preparations. In most experiments, the SD values are covered by the symbol.

inhibition level of isolated enzymes does not correspond with inhibition observed in cells.

No effects were observed on the basal activity recorded just before the addition of the calcium ionophore. This observation suggests that, at the concentration of compounds studied, the complexes do not uncouple the calcium accumulation from the ATP hydrolysis of the native vesicles from the sarcoplasmic reticulum calcium pump. Recent studies demonstrated that vanadium citrate complexes are weak inhibitors of the calcium ATPase with an $\mathrm{IC}_{50}$ of 500 $\mu \mathrm{M}^{25}$ By comparison, under identical experimental conditions as used here, a metavanadate solution results in an $\mathrm{IC}_{50}$ value of $80 \mu \mathrm{M}$ (data not shown). Therefore, we conclude that the BMOV and $\mathrm{PDC}-\mathrm{V}(\mathrm{V})$ complexes are stronger inhibitors of the calcium pump than the most-potent oxovanadates. Given these observations, we investigated the interaction of the vanadium species that existed under the assay conditions in the presence of the SR preparation.

The ${ }^{51} \mathrm{~V}$-NMR spectra of the PDC-V(V) complex in the medium shows a single resonance at -534 ppm (Figure 3 ) with a half-line width of $120 \pm 10 \mathrm{~Hz}$. This chemical shift 


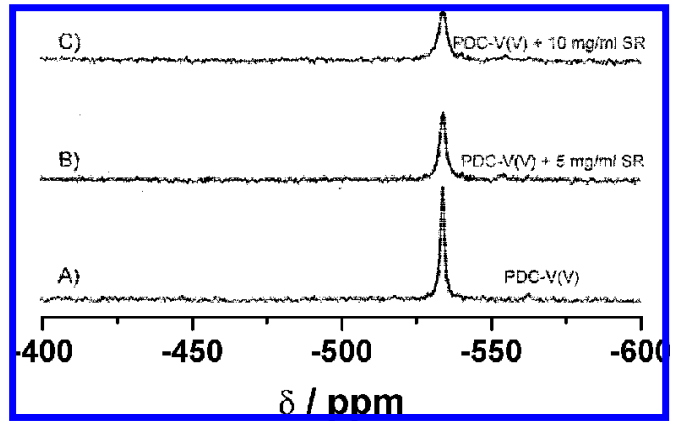

Figure 3. ${ }^{51} \mathrm{~V}-\mathrm{NMR}$ spectra (105.2 MHz) of $4 \mathrm{mM}$ PDC-V(V) complex in a medium containing $25 \mathrm{mM}$ HEPES pH 7.0, $0.1 \mathrm{M} \mathrm{KCl}, 5 \mathrm{mM} \mathrm{MgCl}_{2}$, in the absence $(\mathrm{A})$ or in the presence of sarcoplasmic reticulum vesicles (5 $\mathrm{mg} / \mathrm{mL}$ total protein $(\mathrm{B})$ or $10 \mathrm{mg} / \mathrm{mL}(\mathrm{C})$.

is close to the $-531 \mathrm{ppm}$ reported for the PDC $-\mathrm{V}(\mathrm{V})$ complex in aqueous solution ${ }^{16}$ and demonstrates that this is the species present under assay conditions. Addition of sarcoplasmic reticulum vesicles (up to $10 \mathrm{mg} / \mathrm{mL}$ ) to the $\mathrm{PDC}-\mathrm{V}(\mathrm{V})$ solution in the reaction medium results in significant line broadening (up to $300 \mathrm{~Hz}$ ) and decrease in intensity of the ${ }^{51} \mathrm{~V}-\mathrm{NMR}$ signal with increasing protein concentration (parts B and C of Figure 3). Signal broadening has previously been observed when vanadium derivatives interact with proteins. ${ }^{47-49}$ There was no significant change in chemical shift in the spectra as protein concentration was increased. The solution was very sensitive to temperature and vanadate oligomers formed when slight-heating was used during solution preparation. In this case, besides the resonance at $-534 \mathrm{ppm}$, signals were observed at -560 , -574 , and $-578 \mathrm{ppm}$ due to monomeric $\left(\mathrm{V}_{1}\right)$, dimeric $\left(\mathrm{V}_{2}\right)$, and to cyclic tetrameric $\left(\mathrm{V}_{4}\right)$ vanadate species (data not shown), respectively. Because sucrose is often present in the SR preparations, spectra were acquired in the presence of sucrose. No broadening of the NMR signal was detected by the addition of the equivalent amounts of sucrose to those present in the SR preparations (data not shown). These results indicate that the observed line broadening is due to vanadium complex interaction with the SR preparation.

The possibility that signal broadening may be due to components in the SR-vesicles other than the calcium pump was considered. Significant amounts of glycogen phosphorylase $(16 \%)$ and calsesquestrin $(10 \%)$ besides others proteins (as observed by SDS-PAGE gel electrophoreses) may be present in these preparations. Previous studies with glycogen phosphorylase indicate that this enzyme interacts with vanadate; however, the interaction is not extensive (unpublished data ${ }^{50}$ ). Although vanadate does interact with other proteins, significant amounts of protein must generally be present to result in the observed line broadening. ${ }^{5,23,24,51,52}$ Therefore, although these studies do not rule out that these

(47) Butler, A.; Danzitz, M. J.; Eckert, H. J. Am. Chem. Soc. 1987, 109, 1864-1865.

(48) Stankiewicz, P. J.; Gresser, M. J.; Tracey, A. S.; Hass, L. F. Biochemistry 1987, 26, 1264-1269.

(49) Wittenkeller, L.; Lin, W.; Diven, C.; Ciaccia, A.; Wang, F.; Mota de Freitas, D. Inorg. Chem. 2001, 40, 1654-1662.

(50) Drueckhammer, D. G.; Durrwachter, J. R.; Pederson, R. L.; Crans, D. C.; Daniels, L.; Wong, C.-H. J. Org. Chem. 1989, 54, 70-77.

(51) Crans, D. C.; Rithner, C. D.; Baruah, B.; Gourley, B. L.; Levinger, N. E. J. Am. Chem. Soc. 2006, 128, 4437-4445.

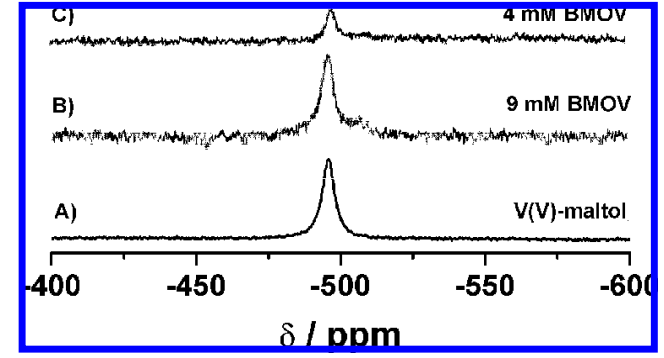

Figure 4. ${ }^{51} \mathrm{~V}-\mathrm{NMR}$ spectra $(105.2 \mathrm{MHz})$, at $22{ }^{\circ} \mathrm{C}$, of $9.0 \mathrm{mM}$ $\left[\mathrm{VO}_{2}(\mathrm{ma})_{2}\right]^{-}(\mathrm{V}(\mathrm{V})$-maltol) (A) in aqueous solution, $9.0 \mathrm{mM}(\mathrm{B})$, and 4.0 $\mathrm{mM}(\mathrm{C})$ BMOV complex solution prepared in the reaction medium; the spectra observed in (B) and (C) represent the oxidized forms of BMOV.

interactions with the vanadium complexes exist, the magnitude of the observed response would require a protein with an exceedingly strong affinity for vanadate to exhibit the observed effect.

The possibility that the line broadening is caused by association of the compounds with the lipid arrangement (assembly) in the SR-vesicle was also considered. We have previously observed that $\mathrm{PDC}-\mathrm{V}(\mathrm{V})$ is able to penetrate a model lipid surface. ${ }^{51}$ In the model system, line broadening of the PDC $-\mathrm{V}(\mathrm{V})$ signal was attributed to immobilization of the compound because proton 2D NOESY spectroscopy studies demonstrated that the protons on the aromatic ring were near the lipid tail group, and thus the complex penetrates the nonpolar layer. ${ }^{51,52}$ In the studies with the SRvesicle, line broadening may also occur because of this type of interaction. However, because the concentration of lipid in the assay is small and the vanadium complex is in large excess, the lipid interaction in these preparations is not likely able to support the $4 \mathrm{mM}$ PDC $-\mathrm{V}(\mathrm{V})$ complex used in these studies. These considerations are consistent with attributing line broadening of the complex signal primarily to interaction with the $\mathrm{Ca}^{2+}$-ATPase.

The BMOV solutions contain vanadium(IV) species observable by EPR spectroscopy (data not shown) consistent with reports describing the solution properties of this compound. ${ }^{40}$ In addition, BMOV is known to oxidize in the presence of oxygen and form the corresponding $\mathrm{V}(\mathrm{V})-$ maltol, $\left[\mathrm{VO}_{2}(\mathrm{ma})_{2}\right]^{-}$complex (part A of Figure 4). ${ }^{40,53}$ The oxidation of BMOV under the assay conditions described in this work immediately result in the formation of $\left[\mathrm{VO}_{2}(\mathrm{ma})_{2}\right]^{-}$(parts $\mathrm{B}$ and $\mathrm{C}$ of Figure 4); however, even after $24 \mathrm{~h}$, less than $50 \%$ of BMOV oxidized in cell-free samples. It is known that such oxidation is much less after administration of BMOV to cells and animals. ${ }^{40,54}$ Studies, using ${ }^{51} \mathrm{~V}$ NMR spectroscopy, were conducted to monitor how much of the BMOV oxidized to form $\left[\mathrm{VO}_{2}(\mathrm{ma})_{2}\right]^{-}$complex and oxovanadates and to demonstrate that placement in the assay medium did not impact the complex otherwise. The spectrum presented in Figure 4 has a signal at $-495 \mathrm{ppm}$ that is

(52) Crans, D. C.; Baruah, B.; Levinger, N. E. Biomed. Pharmacother. 2006, 60, 174-181.

(53) Elvingson, K.; González Baró, A.; Pettersson, L. Inorg. Chem. 1996, 35, 3388-3393.

(54) Amin, S. S.; Cryer, K.; Zhang, B.; Dutta, S. K.; Eaton, S. S.; Anderson, O. P.; Miller, S. M.; Reul, B. A.; Brichard, S. M.; Crans, D. C. Inorg. Chem. 2000, 39, 406-416. 


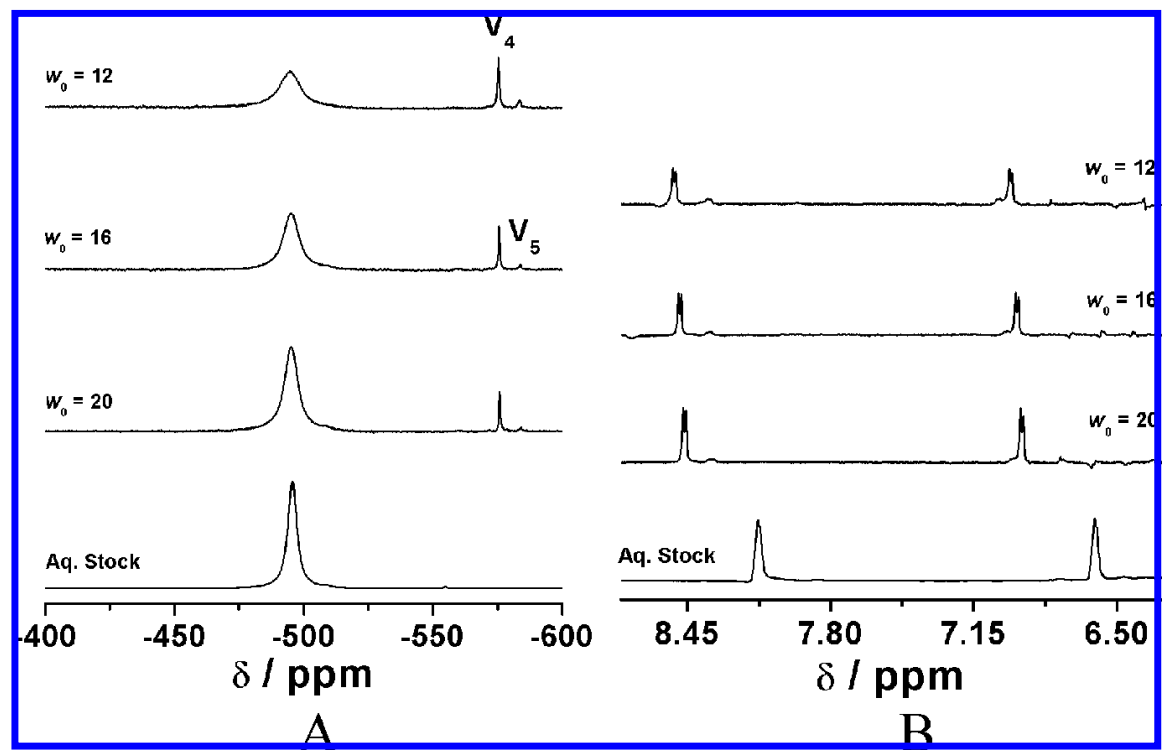

Figure 5. ${ }^{51} \mathrm{~V}$ (panel A) and ${ }^{1} \mathrm{H}$ (panel B) NMR spectra of $\left[\mathrm{VO}_{2}\left(\mathrm{ma}_{2}\right]^{-}\right.$in $\mathrm{D}_{2} \mathrm{O} / \mathrm{AOT} /$ isooctane microemulsions with $w_{\mathrm{O}}=12,16$, and 20 . Stock $\left[\mathrm{VO} 2(\mathrm{ma})_{2}\right]^{-}$ solution was prepared from $60 \mathrm{mM}$ of $\mathrm{NaVO}_{3}$ and $120 \mathrm{mM}$ of maltol at $\mathrm{pH}$ 7.6. Reverse micelles were prepared by adding a calculated volume of $\mathrm{pH}-$ adjusted aqueous stock solutions to a calculated volume of $0.2 \mathrm{M}$ AOT stock solution in isooctane, followed by vortexing to yield an optically transparent homogeneous solution.

Table 1. ${ }^{51} \mathrm{~V}$ NMR Parameters for $\left[\mathrm{VO}_{2}(\mathrm{ma})_{2}\right]^{-}$in Aqueous Solution Prepared from $60 \mathrm{mM} \mathrm{NaVO}$ and $120 \mathrm{mM}$ maltol at $\mathrm{pH} 7.6$ and Microemulsions size $\left(\mathrm{D}_{2} \mathrm{O} / \mathrm{AOT} / \mathrm{Isooctane} \mathrm{RMs}\right)$ Prepared from $0.2 \mathrm{M}$ AOT in Isooctane as Described in Figure 5

\begin{tabular}{lccr}
\hline$w_{0}{ }^{a}$ & chemical shift $(\mathrm{ppm})$ & linewidth $(\mathrm{Hz})$ & \multicolumn{1}{c}{$r_{\mathrm{h}}(\mathrm{nm})^{b}$} \\
\hline stock & -495.6 & $420 \pm 3$ & \\
20 & -495.2 & $630 \pm 6$ & $12.5 \pm 0.3$ \\
16 & -495.2 & $732 \pm 7$ & $6.4 \pm 0.4$ \\
12 & -494.6 & $960 \pm 12$ & $5.7 \pm 0.1$
\end{tabular}

${ }^{a} w_{0}=\left[\mathrm{H}_{2} \mathrm{O}\right] /[$ surfactant $]$; this is a term used to describe the microemulsions. ${ }^{46 b} r_{\mathrm{h}}$ is the diameter of the reverse micelle measured using DLS. $^{46}$

consistent with formation of the most stable $\mathrm{V}(\mathrm{V})$ - maltol complex near neutral $\mathrm{pH}^{40}$

In addition to the major oxidation product of $\mathrm{BMOV}$, $\left[\mathrm{VO}_{2}(\mathrm{ma})_{2}\right]^{-},($at $-495 \mathrm{ppm}$, a second signal near $-509 \mathrm{ppm}$ is observed and attributed to $\left[\mathrm{VO}_{2}(\mathrm{ma})\left(\mathrm{H}_{2} \mathrm{O}\right)_{2}\right]$ (Figure 4). Equilibration of these two $\mathrm{V}(\mathrm{V})$ - maltol will cause some line broadening between the signals, and the presence of the paramagnetic BMOV in these solutions can further increase the relaxation rates, which contributes to line broadening. For comparison, the spectrum is shown of an aqueous solution of $\left[\mathrm{VO}_{2}(\mathrm{ma})_{2}\right]^{-}$(part A of Figure 4), demonstrating that less line broadening is in fact observed under the conditions of the enzyme assay.

When the solution of $\left[\mathrm{VO}_{2}(\mathrm{ma})_{2}\right]^{-}$is placed in a microemulsion (Figure 5), the signal is broadened. In addition to the $\left[\mathrm{VO}_{2}(\mathrm{ma})_{2}\right]^{-}$signal, a signal for oxovanadates $(\sim-555$ ppm) appeared. This observation suggests that the stability of $\left[\mathrm{VO}_{2}(\mathrm{ma})_{2}\right]^{-}$is lower in the microemulsions, and the complex hydrolyzed to form both $\mathrm{V}_{4}$ and $\mathrm{V}_{5}$ oxovanadates. Whether the $\mathrm{V}(\mathrm{V})$-maltol complexes are similar to the $\mathrm{PDC}-\mathrm{V}(\mathrm{V})$ complex $^{51}$ in ability to penetrate the lipid interface can now be considered. As shown in Figure 5, both the ${ }^{51} \mathrm{~V}$ (A) and the ${ }^{1} \mathrm{H}$ (B) NMR signals shifted and broadened in the microemulsion environment. In Table 1, the line widths of the $\left[\mathrm{VO}_{2}(\mathrm{ma})_{2}\right]^{-}$signal for the corresponding sizes of the RM are shown. The line width of the
$\left[\mathrm{VO}_{2}(\mathrm{ma})_{2}\right]^{-}$signal increases from $420 \mathrm{~Hz}$ in aqueous solution at pH 7.6 to more than double in small RMs, and, importantly, as the water pool of the RM increases the line width of the complex approaches that in aqueous solution. The ${ }^{1} \mathrm{H}$ NMR spectra (part B of Figure 5) also show a significant shift upon placement of $\left[\mathrm{VO}_{2}(\mathrm{ma})_{2}\right]^{-}$in the RM and a small but continuous shift as the RM size decreases, consistent with the increased interaction with the lipid interface. The change in the line width is indicative of the $\left[\mathrm{VO}_{2}(\mathrm{ma})_{2}\right]^{-}$complex being located in the water pool possible closely associated with the lipid interface in these structures and not as PDC-V(V), which penetrated into the lipid portion of the interface. The large downfield changes in the ${ }^{1} \mathrm{H}$ NMR chemical shifts are in contrast to the small upfield changes in the ${ }^{51} \mathrm{~V}$ chemical shifts. However, as previously reported, the downfield ${ }^{1} \mathrm{H}$ NMR shift is consistent with interaction with the lipid interface, ${ }^{58,59}$ although we have recently found some inconsistencies with these empirical correlations. ${ }^{51} \mathrm{We}$ conclude that our experiments in microemulsions are consistent with $\mathrm{PDC}-\mathrm{V}(\mathrm{V})$ penetrating the lipid interface, whereas $\left[\mathrm{VO}_{2}(\mathrm{ma})_{2}\right]^{-}$is more associated with the aqueous pool interface.

We conclude that the observed inhibition of the ATPase is caused by solutions containing BMOV and two $\mathrm{V}(\mathrm{V})-$ maltol complexes, and either of these complexes or a combination thereof could be the inhibiting species of the ATPase. Regardless of the differential affinity of these complexes for lipids, because the $\mathrm{PDC}-\mathrm{V}(\mathrm{V})$ and $\mathrm{BMOV}$ systems have very similar affinity for the $\mathrm{Ca}^{2+}$-ATPase, and $\mathrm{PDC}-\mathrm{V}(\mathrm{V})$ and $\left[\mathrm{VO}_{2}(\mathrm{ma})_{2}\right]^{-}$have differential level of penetration of the lipid interface in microemulsions, it follows that the inhibiting species in the BMOV system for the $\mathrm{Ca}^{2+}$ ATPase is not likely to be the $\left[\mathrm{VO}_{2}(\mathrm{ma})_{2}\right]^{-}$complex, the BMOV oxidation product.

In contrast to the other two complexes investigated in this study, the HAIDA-V(IV) solutions only contains the V(IV) 
compound added to solutions, as confirmed by EPR spectroscopy (data not shown). ${ }^{28,41}$ No ${ }^{51} \mathrm{~V}$ NMR signal was detected, consistent with all the vanadium remaining in the form of the original V(IV) complex. This spectrum is consistent with no observable oxidation to a vanadium(V) complex under these assay conditions and is in agreement with previous studies. ${ }^{29,30}$

Combined, these studies show that the calcium pump has a great affinity for PDC-V(V) and BMOV. These compounds are the most effective insulin-enhancing compounds examined, and we point to the possibility that there is a correlation between insulin-enhancing properties and inhibition of $\mathrm{Ca}^{2+}$-ATPase activity. However, more studies are needed to substantiate such a hypothesis further. Because these complexes are known to undergo hydrolytic and redox chemistry under physiological conditions, such conversions are anticipated under our experimental conditions. The affinity of $\mathrm{Ca}^{2+}$-ATPase for the PDC-V(V) and BMOV systems is similar to that reported previously for decavanadate $\left(\mathrm{V}_{10}\right)$, an oxovanadate species recently found to be stabilized the calcium pump and also by actin. ${ }^{55} \mathrm{~V}_{10}$ also is found to affect mitochondria at nanomolar concentrations and induce changes in oxidative stress markers after in vivo administration. ${ }^{11,55-57}$ The calcium pump has previously been found to be inhibited by the vanadium citrate complex; ${ }^{25}$ however, the studies shown here demonstrate more potent interactions with the PDC-V(V) and BMOV systems. Recent studies demonstrated that the redox properties of the vanadium complexes are important to their insulin-enhancing action. ${ }^{16}$ The studies presented show that the greatest inhibition is observed for vanadium compounds with greater insulin-enhancing effects. Although a trend should be based on investigation of more compounds, these observations are consistent with the proposed modes of inhibition of the $\mathrm{Ca}^{2+}$ ATPase by BMOV and PDC- $\mathrm{V}(\mathrm{V})$ involving the compounds' coordination chemistry.

Whether the vanadates act by forming a transition-state complex or binding as a substrate analogue depends on the specific enzyme. ${ }^{6}$ Many phosphorylases are inhibited by vanadate, and the mode of inhibition is the formation of a stable transition-state complex. ${ }^{26}$ ATPases that catalyze ATP hydrolysis while translocating specific ions are referred to as pumps. For these enzymes that are inhibited by vanadate, the mechanism is through trapping the vanadate at the phosphate site accompanied by slow release, assuring reduced catalytic turnover and inhibition of the enzyme activity. ${ }^{1-9,11}$ The SR $\mathrm{Ca}^{2+}$-ATPase catalysis proceeds through a noncovalent phosphoenzyme intermediate as has

(55) Ramos, S; Manuel, M; Tiago, T.; Duarte, R.; Martins, J. A.; GutierrezMerino, C. J.; Moura, J. J. G.; Aureliano, M. J. Inorg. Biochem. 2006, $100,1734-1743$.

(56) Aureliano, M.; Soares, S. S.; Tiago, T.; Ramos, S.; Gutierrez-Merino, C. In Vanadium: The Versatile Metal; Kustin, K., Pessoa, J. C., Crans, D. C., Eds., ACS Symposium Series, Vol. 974, Chapter 18, 249-263. American Chemical Society, Washington, DC, 2007.

(57) Soares, S. S.; Henao, F.; Aureliano, M.; Gutierrez-Merino, C. $\underline{\text { Chem. }}$ Res. Toxicol. 2008, 21, 607-618.

(58) Vermathen, M.; Chodosh, A. B.; Louis, E. A.; Simonis, U. J. Inorg. Biochem. 1999, 74, 328.

(59) Vermathen, M.; Chodosh, A. B.; Ried, S.; Simonis, U. Langmuir 2000, $16,210-221$. been observed for other ATPases and phosphorylases and subsequent formation of a phosphorylenzyme intermediate during ATP hydrolysis. ${ }^{10}$ In the absence of ATP and calcium, for this ATPase vanadate is proposed to bind in the vicinity of the aspartyl phosphate acceptor so as to block the active site and thus prevent phosphoenzyme intermediate formation, ultimately trapping the enzyme in the E2 conformation. ${ }^{9,11}$ Phosphorylation of the SR calcium pump by ATP, and conversion to the E1-P conformation, decreases the affinity of specific oxovanadates for the enzyme. This is consistent with the vanadate binding sites being in the region of the phosphorylation site. ${ }^{9}{ }^{11}$ Other modes of action have been reported such as vanadate binding in a manner similar to an ATP analogue. ${ }^{6}$ Vanadium-containing complexes have the potential to act through mechanisms similar to the simple oxovanadates if they can hydrolyze to form oxovanadate while in the presence of the enzyme.

Monomeric vanadate is not the only form of oxovanadates that can interact with these enzymes. ${ }^{6}$ The interaction of decavanadate with the $\mathrm{Ca}^{2+}$-ATPase has been reported, and unlike vanadate, such inhibition is not affected by ATP or $\mathrm{Ca}^{2+}{ }^{11}$ Therefore, SR ATPase conformational changes in the presence of vanadium species can explain why the different affinities for the protein are observed. For monomeric vanadate, the $\mathrm{E} 2$ conformation of the calcium pump is favorable; however, $\mathrm{V}_{10}$ appears to interact with either the E1 or E1-P conformation. ${ }^{11}$ Moreover, it is known that oxovanadates bind to enzymes surfaces with positive charges, ${ }^{9,32}$ namely lysine and arginine residues, locking the enzyme in a specific conformation and in such a manner inhibiting the enzyme activity. ${ }^{32,56}$ In this work, we report the inhibition of $\mathrm{Ca}^{2+}$-ATPase by three vanadium coordination complexes. Because all three complexes cause inhibition of the calcium pump different from that of the simple oxovanadates, these results suggest that their mode of action is different than the uncomplexed vanadium.

\section{Conclusions}

A combination of inhibition studies, ${ }^{51} \mathrm{~V}$ NMR, and EPR spectroscopy was used to determine the interaction of vanadium complexes with the calcium pump. The effects of three well-characterized complexes, the pyridine-2,6-dicarboxylatodioxovanadium(V) (PDC- $\mathrm{V}(\mathrm{V}))$, bis(maltolato)oxovanadium(IV) (BMOV), and bis( $N$-hydroxylamidoiminodiacetato)vanadium(IV) (HAIDA-V(IV)), on SR preparations of the calcium pump from sarcoplasmic reticulum were determined. Because BMOV partially oxidizes into vanadi$\mathrm{um}(\mathrm{V})$ species, and the PDC- $\mathrm{V}(\mathrm{V})$ complex in part hydrolyzes into different amounts of monomeric $\left(\mathrm{V}_{1}\right)$; dimeric $\left(\mathrm{V}_{2}\right)$ and tetrameric $\left(\mathrm{V}_{4}\right)$ species, the complexes were monitored in the enzyme assay medium. Because of the chemistry of the chosen insulin-enhancing compounds under physiological conditions, a third complex that is expected to be more resistant to the reaction conditions, HAIDA-V(IV), was also investigated. The order of the inhibition of the calcium ATPase activity by the complexes is $\mathrm{PDC}-\mathrm{V}(\mathrm{V}) \geq \mathrm{BMOV}$ $>$ HAIDA-V(IV), with $\mathrm{IC}_{50}$ values of $25 \mu \mathrm{M}, 40 \mu \mathrm{M}$, and $325 \mu \mathrm{M}$, respectively. These affinities are much greater than 
the effects of the vanadium citrate complex that inhibits the calcium ATPase activity with an $\mathrm{IC}_{50}$ of $0.5 \mathrm{mM} .^{25}$ For comparison, a vanadate solution (prepared from metavanadate) has an $\mathrm{IC}_{50}$ of $80 \mu \mathrm{M}$. It is important to note that the most potent inhibition was observed for the complexes that can undergo oxidative or hydrolytic reactions under the conditions of the assay, whereas the HAIDA-V(IV) complex is a much less effective inhibitor. These observations are significant because these compounds and their differential inhibitory activities may serve as useful probes for unravelling complex catalytic details for the $\mathrm{Ca}^{2+}$-ATPases.

Because the $\mathrm{PDC}-\mathrm{V}(\mathrm{V})$ and $\mathrm{BMOV}$ complexes convert into other species under the assay conditions, the presence of the complexes in the assay medium was monitored. The target compounds and other decomposition compounds were observed in the medium. Because the complexes convert into other species in the reaction medium and none of these species are more potent than these coordination complexes, the simple oxovanadate decomposition products are not causing most of the inhibition. The well-known inhibition of phosphorylases by vanadate through formation of a transition-state analogue generally involves a covalent complex. Thus, in many cases, such observations can readily be attributed to the hydrolysis of such complexes to simple vanadate. The studies presented here deviate from this description in that two of the coordination complexes, $\mathrm{PDC}-\mathrm{V}(\mathrm{V})$ and $\mathrm{BMOV}$, are more potent than the simple oxovanadate, monomeric vanadate. Because no decomposition products were observed for the HAIDA-V(IV) complex, the observed inhibition can be attributed exclusively to this complex. Importantly, this coordination complex was less effective than oxovanadate in inhibiting the calcium pump.
Because $\mathrm{Ca}^{2+}$-ATPase can adopt several conformations, the specific nature of the interactions of each of the vanadium species with the sarcoplasmic reticulum $\mathrm{Ca}^{2+}$-ATPase is beyond the scope of this investigation. However, inhibition by BMOV and PDC-V(V) was unchanged by ATP or $\mathrm{Ca}^{2+}$, two effectors of enzyme in the E1 and E1-P conformation, indicating a very different mode of action from that of vanadate. These insulin-enhancing complexes that readily undergo hydrolytic reactions were found to be more potent inhibitors than the simple salt (vanadate). In contrast, the HAIDA-V(IV) complex is a less-potent inhibitor. These facts are consistent with the inhibition of the $\mathrm{Ca}^{2+}$-ATPase by the vanadium compounds and involve adduct formation between protein and the vanadium compound. These findings are also consistent with the mechanism of the inhibition by vanadate being through complexation of the vanadium atom to the catalytic site of $\mathrm{Ca}^{2+}$-ATPase.

Acknowledgment. This work has been supported by Joint Spanish-Portuguese Project CRUP-E-106/05 and by the POCTI program financed through FEDER: project 38191/ QUI/2001 (M.A.). D.C.C. thanks the National Institutes of Health (NIGMS GM-50525) and the American Heart Association (0650081Z) for funding. Dr. T. Tiago is the recipient of a postdoctoral fellowship (SFRH/BPD/20777/ 2004) from the Portuguese Foundation for Science and Technology (F.C.T.). We thank Prof. Sandra J. Bonetti for reading this manuscript and for helpful discussions.

IC702405D 